\title{
Venous Thromboembolism in Cancer Patients: Comparison of Lung Cancer Patients to Other Solid Tumor Patients in a Prospective Observational Study
}

\author{
Carme Font ${ }^{1}$, Marc Campayo ${ }^{1}$, Blanca Farrus ${ }^{2,4}{ }^{4}$, Alberto Carmona-Bayonas ${ }^{1}$, \\ Aranzazu Fernández-Martinez ${ }^{1}$, Noemi Reguart ${ }^{1,4}$, Dolors Tassies ${ }^{3}$, \\ Nuria Viñolas ${ }^{1,4}$, Joan C Reverter ${ }^{3,4,5}$ and Pere Gascon ${ }^{1,4,5}$ \\ ${ }^{1}$ Medical Oncology Department, Barcelona, Spain \\ ${ }^{2}$ Radiation Oncology Department, Barcelona, Spain \\ ${ }^{3}$ Hemotherapy and Hemostasis Department, Hospital Clinic, Barcelona, Spain \\ ${ }^{4}$ Institut d'Investigacions Biomèdiques August Pi i Sunyer (IDIBAPS), Barcelona, Spain \\ ${ }^{5}$ University of Barcelona, Barcelona, Spain
}

Received 29 September 2012; Accepted 7 January 2013; Published 18 February 2013

Academic Editor: Mirko H. Hirschl

Funding Sources: This study was supported in part by Grants FIS PI070387 from the Fondo de Investigaciones Sanitarias, Instituto de Salud Carlos III, Spain.

\begin{abstract}
Background: Lung cancer (LC) is the most frequent solid tumor diagnosed worldwide and is one of the most common tumors in series of patients with cancer-related venous thromboembolism (VTE). The aim of this study was to analyze the clinical characteristics and outcome of VTE in patients with LC compared to patients with other types of cancer (OC).

Patients and Methods: A prospective observational study enrolling consecutive cancer patients with newly diagnosed VTE was performed from May 2006 to April 2009 in our Department of Medical Oncology. All patients were uniformly treated and followed according to the American College of Chest Physicians guidelines.
\end{abstract}

Copyright (C) 2012 Carme Font, Marc Campayo, Blanca Farrus, Alberto Carmona-Bayonas, Aranzazu Fernández-Martinez, Noemi Reguart, Dolors Tassies, Nuria Viñolas, Joan C Reverter and Pere Gascon. This is an open access article distributed under the Creative Commons Attribution License unported 3.0, which permits unrestricted use, distribution, and reproduction in any medium, provided that original work is properly cited. Contact author: Refad Rofael E-mail: cfont@clinic.ub.es

How to Cite this Article: Carme Font, Marc Campayo, Blanca Farrus, Alberto Carmona-Bayonas, Aranzazu Fernández-Martinez, Noemi Reguart, Dolors Tassies, Nuria Viñolas, Joan C Reverter and Pere Gascon, "Venous Thromboembolism in Cancer Patients: Comparison of Lung Cancer Patients to Other Solid Tumor Patients in a Prospective Observational Study," Advances in Cancer: Research \& Treatment, vol. 2012, Article ID 223916, 12 pages

DOI: $10.5171 / 2012.223916$ 
Results: A total of 340 cancer patients were enrolled with LC being the most frequent primary tumor in $89(26 \%)$ patients (69 male; mean age $62 \pm 11$ years). VTE was diagnosed earlier in patients with LC after the initial cancer diagnosis, with a median of 4 months (95\% CI 2.79$5.20)$ compared to 7 months $(95 \%$ CI $4.40-9.59)$ in patients with OC $(\mathrm{p}<0.0001)$. The VTE presented as pulmonary embolism in a higher proportion of patients with LC $(51 \%$ vs $28 \%$, $\mathrm{p}=0.005$ ) although there were no differences in VTE-related outcomes due to the acute thrombotic event. After a mean follow-up of $14 \pm 13$ months no significant differences were found in venous re-thrombosis, major-bleeding or causes of death in patients with LC and OC.

Conclusion: VTE in patients with LC occurs earlier after cancer diagnosis although no differences in VTE-related outcomes were observed compared to patients with OC.

Keywords: Venous thromboembolism; Hypercoagulability; Lung Cancer; Trousseau's syndrome.

\section{Introduction}

Venous thromboembolism (VTE) including deep vein thrombosis (DVT) and pulmonary embolism (PE) is a leading cause of death and morbidity in cancer patients. Several risk factors for developing venous thrombosis usually coexist in cancer patients including surgery, hospital admissions and immobilization, the presence of an indwelling central catheter, chemotherapy, use of erythropoiesisstimulating agents (ESA) and new molecular targeted therapies such as antiangiogenic agents as reviewed by Lee et al (2003) and Prandoni et al (2005). In addition to the above mentioned clinical factors, the presence of tumor cells induces a hypercoagulable state by producing procoagulant, fibrinolytic, and proaggregating activities, by releasing proinflammatory and proangiogenic cytokines, and by interacting directly with endothelial cells, platelets and leukocytes (Rickles et al, 2006). Furthermore, Winter et al (2006) reviewed how the activation of the hemostatic system promotes tumor growth, angiogenesis and invasive behaviour. In fact, the development of VTE patients has been associated with a higher risk of death as observed by Sorensen et al (2000). This association may due to both mortality directly associated with the thrombotic event itself as well as a greater biological aggressivity of the tumor in patients who develop VTE.

Rates of VTE vary markedly among cancer patients depending on specific histological grade, cancer stage and anticancer therapies. Due to the absolute high number of patients with lung cancer (LC), this group is of particular clinical interest. LC is the most common cause of cancer-related death worldwide (Jemal et al, 2009). Patients with LC show a high prevalence of VTE as observed by different authors (Blom et al 2004, Tagalakis et al 2007 and Chew et al 2007) being one of the most common tumors in series of patients with cancer-related VTE (Seddighzadeh et al 2007, White at al 2005 and Paneesha et al 2010). The thrombotic risk in patients with LC is 20 -fold higher than in the general population according to findings by Blom et al (2004). Among patients with LC, some factors have been associated with the development of VTE: adenocarcinoma type, metastatic disease, pneumonectomy and anticancer therapies including chemotherapy and anti-angiogenic targeted therapies as reviewed by Tesselaar et al (2007).

The present study was aimed to describe the epidemiology, clinical characteristics and the outcome of VTE in cancer patients with LC compared to other types of cancer (OC). Among patients with LC we analyzed specific VTE-related outcomes with regard to histological subtypes.

\section{Materials and Methods}

A prospective observational study consecutively enrolling patients over the age of 18 years with histologicallyconfirmed solid tumors and newly- 
diagnosed VTE, was carried out from May 2006 to April 2009 in our Medical Oncology Department. Patients were eligible for inclusion if they had either active cancer (locorregional or metastatic disease) or developed VTE while receiving chemotherapy in the adjuvant setting. The study was approved by the local Ethics Committee and all patients provided written informed consent to participate.

Patients were recruited in the cancer outpatient clinic (clinically-stable patients attended during the daytime from Monday to Friday), the Emergency Department (clinically unstable patients and/or during nights and weekends) or in the Medical Oncology ward for hospitalized patients.

All VTE events were confirmed using objective radiological methods: venous ultrasonography, ventilation/perfusion pulmonary scintigraphy, phlebography and/or high-resolution CT scans, including both scheduled CT scans for cancer evaluation and CT scans with pulmonary angiography (CTPA) to depict PE in patients with symptoms suggestive of PE. Patients were consecutively recruited irrespective of whether VTEs were labelled as incidental or symptomatic events.

The new VTE event at study recruitment was named the VTE index. Clinical assessment was recorded on a standardized data collection sheet that included information on clinical symptoms, demographic data, Eastern Cooperative Oncology Group (ECOG) performance status, tumor type and stage (Klimpfinger et al, 1999), specific anticancer therapy received in the two months prior to the diagnosis of VTE (surgery, chemotherapy, radiotherapy, targeted therapies and/or hormonotherapy), catheter insertion and use of erythropoiesis-stimulating agents (ESA) at the time of the VTE index event.

Anticoagulant therapy was prescribed by the treating oncologists according to current international recommendations at the time of the study (Büller et al 2004, Kearon C et al 2008). Low molecular weight heparin (LMWH) was the standard anticoagulant therapy during the first 3 months after the VTE index event. Subsequently, LMWH was also routinely recommended for 6 to 12 months or even indefinitely for patients with active neoplastic disease and/or those receiving chemotherapy. In patients with incidental VTE anticoagulation was routinely indicated. Whenever possible, outpatient management of the VTE index event was preferred. Criteria for hospital admission were the following adapted of Siragusa et al study (2005): poor clinical conditions due to the VTE event and/or concomitant medical comorbidities, poor compliance, high risk of bleeding or active bleeding, renal insufficiency and platelet count less than $50 \times 10^{9} / \mathrm{L}$.

Follow-up was ongoing up to the death of the patient (including death in the first 24 hours after the VTE index event) or the last follow-up at the time of data analysis (June 2010). The database was updated monthly by the authors according to the clinical information available on scheduled oncologist visits, hospital admissions, electronic health records and/or telephone calls if necessary. The data recorded included maintenance of anticoagulation, venous re-thrombosis, relevant bleeding and date and cause of death.

Venous re-thrombosis during the follow-up was defined as new VTE occurring at another site and/or extension of the thrombus found in the previous baseline evaluation.

A bleeding event was classified as major when it was associated with death, occurred at a critical site (intracranial, intraspinal, intraocular, retroperitoneal, or pericardial area), required blood transfusions or resulted in a fall in hemoglobin of at least $2 \mathrm{gr} / \mathrm{L}$.

\section{Statistical Analysis}

Baseline characteristics of the patients are reported by means, standard deviation (SD), absolute numbers and percentages. Categorical variables were compared using the Chi-square or Fisher's exact test as appropriate. Continuous variables were compared using the Student's t test. 
Median follow-up times were calculated from cancer diagnosis to the VTE index event and from the VTE index event until death or last follow-up.

Major bleeding-free survival, venous rethrombosis-free survival and overall survival were calculated as the time from the VTE index event to major bleeding events, venous re-thrombosis and death respectively or censored data (death or last follow-up) and were estimated using the Kaplan-Meier method. Comparison between the two groups was made using the log-rank test.

Multivariate analyses using stepwise Cox regression using independent variables identified in the univariate analysis was performed. Exp (beta) and their corresponding 95\% confidence intervals (95\% CI) were calculated. Calculations were performed using the SPSS v14 package (SPSS Inc., Chicago, IL, USA).

\section{Results}

\section{Patient Characteristics}

Three hundred and forty cancer patients (192 men and 148 women) with newlydiagnosed VTE were recruited. LC was the most frequent primary tumor in 89 patients $(26 \%)$ followed by colorectal 52 (15\%), breast 49 (14\%), genitourinary system 46 (13\%), gynecological 34 (10\%), upper gastrointestinal 31 (9\%), head and neck 17 (5\%), melanoma 7 (2\%), cancer of unknown origin $7(2 \%)$ and other primary tumor sites in the remaining $8(2 \%)$ patients including 3 sarcomas, 2 thymomas, 2 central nervous system neoplasms and 1 pleural mesothelioma. The baseline epidemiological characteristics and anticancer therapies of patients at the time of recruitment are displayed in Table 1. Patients with LC were more frequently men and smokers, were more likely to have metastatic cancer, had received more ESA and had undergone less major surgery than patients with OC.

Table 1. Baseline Characteristics of Patients with Lung vs. other Types of Cancer

\begin{tabular}{|c|c|c|c|}
\hline & $\begin{array}{c}\text { Lung cancer }(\%) \\
N=89(26 \%)\end{array}$ & $\begin{array}{c}\text { Other cancers (\%) } \\
\mathrm{N}=251(74 \%)\end{array}$ & $\begin{array}{c}P \\
\text { Univariate }\end{array}$ \\
\hline Mean age \pm SD (years) & $62 \pm 11$ & $61 \pm 12$ & NS \\
\hline Gender (M) & $69(77 \%)$ & $123(49 \%)$ & $<0.0001$ \\
\hline Smoking habit & $74(83 \%)$ & $102(41 \%)$ & $<0.0001$ \\
\hline Previous VTE & $4(4 \%)$ & $14(6 \%)$ & NS \\
\hline $\begin{array}{c}\text { ECOG } \\
0 \\
1 \\
2 \\
3 \\
\end{array}$ & $\begin{array}{c}11(12 \%) \\
34(38 \%) \\
35(39 \%) \\
9(10 \%) \\
\end{array}$ & $\begin{array}{l}42(17 \%) \\
97(39 \%) \\
69(27 \%) \\
43(17 \%)\end{array}$ & NS \\
\hline Inpatients & $13(14 \%)$ & $33(13 \%)$ & NS \\
\hline $\begin{array}{l}\text { Cancer stage } \\
\text { Adjuvant setting } \\
\text { Locoregional } \\
\text { Metastatic } \\
\end{array}$ & $\begin{array}{c}5(6 \%) \\
13(15 \%) \\
71(80 \%) \\
\end{array}$ & $\begin{array}{c}47(19 \%) \\
43(17 \%) \\
161(64 \%)\end{array}$ & 0.007 \\
\hline $\begin{array}{l}\text { Anticancer therapies } \\
\text { Major surgery } \\
\text { Chemotherapy } \\
\text { Radiotherapy } \\
\text { Targeted therapies } \\
\text { Hormonotherapy } \\
\text { ESA }\end{array}$ & $\begin{array}{c}5(6 \%) \\
62(70 \%) \\
28(31 \%) \\
5(6 \%) \\
4(5 \%) \\
31(35 \%)\end{array}$ & $\begin{array}{c}41(16 \%) \\
153(61 \%) \\
61(24 \%) \\
7(3 \%) \\
27(11 \%) \\
51(20 \%) \\
\end{array}$ & $\begin{array}{c}0.011 \\
\text { NS } \\
\text { NS } \\
\text { NS } \\
\text { NS } \\
0.006 \\
\end{array}$ \\
\hline
\end{tabular}

Abbreviations: ECOG: Eastern Cooperative Oncology Group classification;

ESA: erythropoietin-stimulating factors;

M: male; 
SD: standard deviation;

VTE: venous thromboembolism.

NS: not significant

\section{LC Histological Types}

Among patients with LC the distribution of histological subtypes was as follows: adenocarcinoma in 42 (47\%), squamous cell carcinoma (SCC) in 19 (21\%), nonsmall-cell lung cancer not otherwise specified (NSCLC-NOS) in 15 (17\%), small cell lung cancer in $9(10 \%)$ and large cell carcinoma in 4 (4\%). We compared the epidemiological characteristics of patients with adenocarcinoma $(n=42)$ to patients with other LC histologies (SCC, NSCLC-NOS, small-cell and large cell; $n=47)$. There were significant differences with regard to cancer staging being adenocarcinoma more likely to have metastatic cancer ( $93 \%$ vs. $68 \% ; \mathrm{p}=0.001$ ) and with respect to the use of ESA at the time of VTE $(22 \%$ in adenocarcinoma vs. $47 \%$ in other LC histologies; $\mathrm{p}=0.018$ ).

\section{Venous Thrombotic Index Events}

Data on the characteristics of the VTE index events are summarized in Table 2.

Table 2. Clinical Characteristics of the Venous Thrombotic Events and Outcome Variables in Patients with Lung vs. other Types of Cancer

\begin{tabular}{|c|c|c|c|}
\hline & $\begin{array}{c}\text { Lung cancer }(\%) \\
\mathrm{N}=89(26 \%)\end{array}$ & $\begin{array}{l}\text { Other cancers }(\%) \\
\quad N=251(74 \%)\end{array}$ & $\mathbf{P}$ \\
\hline $\begin{array}{l}\text { Concomitant diagnosis of cancer and } \\
\text { VTE }\end{array}$ & $16(18 \%)$ & $19(8 \%)$ & 0.006 \\
\hline $\begin{array}{l}\text { Median time to VTE index event } \\
\text { after cancer diagnosis (months) }\end{array}$ & 4 & 7 & $<0.0001$ \\
\hline $\begin{array}{l}\text { Radiological test } \\
\text { Doppler ultrasonography } \\
\text { CTPA } \\
\text { Scheduled CT scan } \\
\text { V/P Scintigraphy } \\
\text { Phlebography } \\
\end{array}$ & $\begin{array}{c}34(38 \%) \\
17(19 \%) \\
33(37 \%) \\
4(5 \%) \\
1(1 \%)\end{array}$ & $\begin{array}{c}126(50 \%) \\
34(14 \%) \\
82(33 \%) \\
8(3 \%) \\
1(0 \%) \\
\end{array}$ & NS \\
\hline VTE event & & & $<0.001$ \\
\hline $\begin{array}{l}\text { DVT } \\
\text { Symptomatic } \\
\text { Incidental }\end{array}$ & $\begin{array}{l}30(34 \%) \\
0\end{array}$ & $\begin{array}{l}99(39 \%) \\
21(8 \%)\end{array}$ & \\
\hline $\begin{array}{l}\text { PE } \\
\text { Symptomatic } \\
\text { Incidental }\end{array}$ & $\begin{array}{l}21(24 \%) \\
24(27 \%)\end{array}$ & $\begin{array}{l}38(15 \%) \\
33(13 \%)\end{array}$ & \\
\hline $\begin{array}{l}\text { Catheter thrombosis } \\
\text { Symptomatic } \\
\text { Incidental }\end{array}$ & $\begin{array}{l}7(8 \%) \\
1(1 \%)\end{array}$ & $\begin{array}{l}37(15 \%) \\
0\end{array}$ & \\
\hline $\begin{array}{l}\text { Vena cava } \\
\text { Symptomatic } \\
\text { Incidental }\end{array}$ & $\begin{array}{l}4(4 \%) \\
1(1 \%)\end{array}$ & $\begin{array}{c}3(1 \%) \\
17(7 \%)\end{array}$ & \\
\hline $\begin{array}{l}\text { CNS venous thrombosis } \\
\text { Symptomatic } \\
\text { Incidental }\end{array}$ & $\begin{array}{c}1(1 \%) \\
0\end{array}$ & $\begin{array}{l}3(1 \%) \\
0\end{array}$ & \\
\hline $\begin{array}{l}\text { Outpatient management of the VTE } \\
\text { index event }\end{array}$ & $50(56 \%)$ & $161(64 \%)$ & NS \\
\hline Death due to VTE index event & $3(3 \%)$ & $3(1 \%)$ & NS \\
\hline $\begin{array}{ll}\text { Abbreviations: VTE: venous thromboembolism } \\
\text { DVT: deep vein thrombosis. } & \text { PE: pul } \\
\text { CT: computed tomography. } & \text { V/P: ve } \\
\text { CNS: central nervous system. } & \text { NS: not }\end{array}$ & $\begin{array}{l}\text { SD: statistical devia } \\
\text { nonary embolism. } \\
\text { tilation/perfusion. } \\
\text { significant }\end{array}$ & & \\
\hline
\end{tabular}


The VTE index event was diagnosed concomitantly to cancer more frequently in patients with LC than in those with OC (18\% vs. 8\%, p=0.006). Moreover, VTE was diagnosed earlier after cancer diagnosis with a median time of 4 months (95\% CI 2.79-5.2) in patients with LC versus 7 months (95\% CI 4.40-9.59) in patients with OC (log-rank $\mathrm{p}<0.001$ ) as shown in Figure
1. In the multivariate analysis of time from cancer diagnosis to VTE index event the best model included the following variables: cancer extension at the time of the VTE index event (adjuvant chemotherapy $=0$, locoregional cancer $=1$, metastatic disease $=2)(p=0.002 ; R R=1.12)$ and having LC (lung cancer $=0$, other cancers $=1)(\mathrm{p}<0.001 ; \mathrm{RR}=1.85)$.

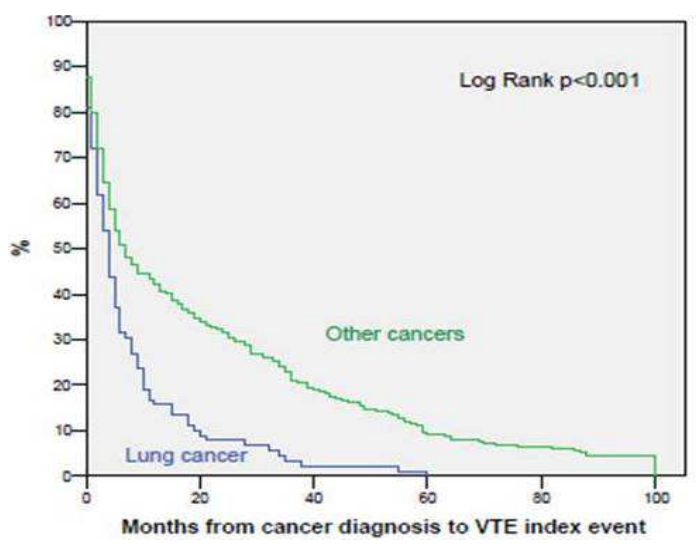

Figure 1. Time from Cancer Diagnosis to VTE Index Event in Patients with Lung vs. Other Types of Cancer

Among patients with LC, the VTE index event was diagnosed earlier in patients with adenocarcinoma, with a median time of 2 months (95\% CI $0.7-3.2$ ) after cancer diagnosis versus 5 months (95\% CI 3.4-6.5) in patients with other LC histologies (logrank $p=0.042$ ) as shown in Figure 2 .
However, when adjusting for cancer extension and use of ESA in the multivariate analysis, no significant differences were found in regard to histological subtype.

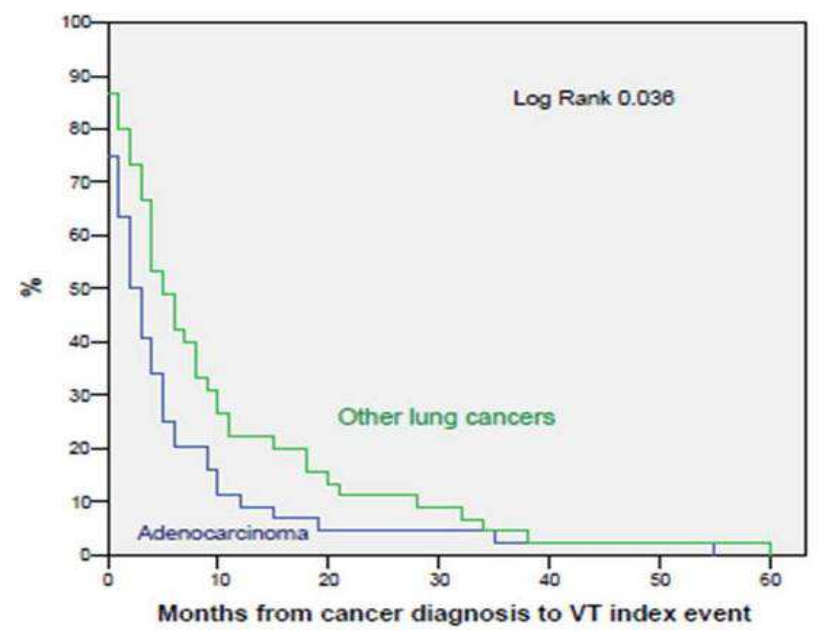



Figure 2. Time from Cancer Diagnosis to VTE Index Event in Patients with
Adenocarcinoma vs. Other LC Histologies.

The proportion of VTE index events incidentally diagnosed by scheduled CT scans for cancer evaluation was similar in both groups $(37 \%$ in LC vs. $33 \%$ in OC, $\mathrm{p}=\mathrm{NS}$ ). Patients with LC more frequently presented with PE as the VTE index event (51\% vs. 28\%, p=0.005) than patients with OC although a similar proportion of patients in both groups fulfilled criteria for outpatient treatment of the VTE index events ( $56 \%$ in LC vs. $64 \%$ in OC, $p=N S$ ). Of note, none of these patients required further hospital admission for complications related to therapy of the acute thrombotic event. Likewise, a similar proportion of deaths due to the VTE index event were observed in both groups $(3 \%$ in LC and $1 \%$ in OC, $\mathrm{p}=\mathrm{NS}$ ).

\section{Clinical Outcome}

Patients were followed a mean time of $14 \pm$ 13 months. Three patients were transferred to another institution during follow-up but relevant clinical information was obtained from the patients and treating physicians by telephone calls. A similar proportion of patients died in our hospital (49\% with LC vs $38 \%$ with OC), died at home or in outside palliative-care facilities ( $43 \%$ with LC vs $47 \%$ with OC) or were lost of follow-up ( $8 \%$ with LC and $15 \%$ with OC; p NS). Table 3 shows the outcome variables.

Table 3. Outcomes in Patients with Lung vs. Other Types of Cancer

\begin{tabular}{|l|c|c|c|}
\hline & $\begin{array}{c}\text { Lung cancer (\%) } \\
\text { N=89 (26\%) }\end{array}$ & $\begin{array}{c}\text { Other cancers (\%) } \\
\mathbf{N = 2 5 1}(\mathbf{7 4 \% )}\end{array}$ & P \\
\hline Mean follow-up \pm SD (months) & $10 \pm 11$ & $18 \pm 16$ & $<0.0001$ \\
\hline Major-bleeding events & $11(12 \%)$ & $33(13 \%)$ & $\mathrm{NS}$ \\
\hline Venous rethrombosis & $16(18 \%)$ & $39(15 \%)$ & $\mathrm{NS}$ \\
\hline Arterial thrombosis & $3(3 \%)$ & $3(1 \%)$ & $\mathrm{NS}$ \\
\hline Deaths & $82(92 \%)$ & $175(71 \%)$ & 0.001 \\
\hline Causes of death & & & $\mathrm{NS}$ \\
Cancer progression & 62 & 131 & \\
Infection & 7 & 9 & \\
Venous thrombosis & 4 & 16 & \\
Bleeding & 5 & 4 & \\
Unrelated to cancer & 1 & & \\
\hline
\end{tabular}

Abbreviations:

SD: statistical deviation.

NS: not significant

Patients with LC had a worse overall survival compared to patients with OC. The overall survival rate at 6 and 12 months was $50 \%$ and $30 \%$ for LC and $65 \%$ and $50 \%$ for OC, respectively (log rank $\mathrm{p}<0.0001)$. However, there were no differences in relation to causes of death in patients with LC compared to patients with OC and in the occurrence of major-bleeding events. The probability of venous rethrombosis tended to be higher in LC. The rethrombosis-free survival rate at 6 and 12 months was $81 \%$ and $78 \%$ for patients with LC and $90 \%$ and $86 \%$ for patients with OC, respectively, although these values did not reach statistical significance $(p=0.064)$ (Figure 3$)$. 


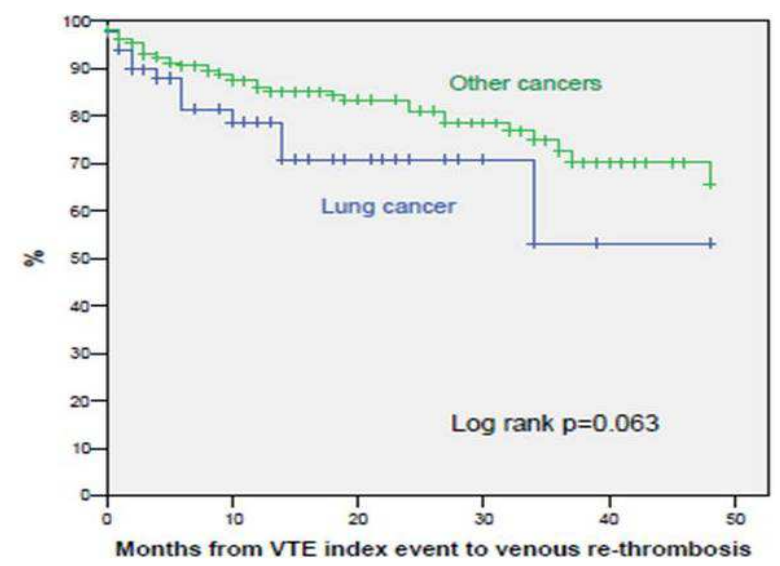

Fig 3. Venous Re-Thrombosis-Free Survival in Patients with Lung vs. Other Types of Cancer

No differences were observed among patients with LC taking into account the histological subtype (adenocarcinoma versus other histological types) with regard to major-bleeding events, venous rethrombosis, and causes of death.

\section{Discussion}

Lung cancer was the most frequent tumor in our series of consecutive cancer patients with VTE occurring in $26 \%$ of our cohort. Although specific factors in each medical institution may influence the proportion of primary tumours, our findings are in agreement with previous studies (Seddighzadeh et al 2007, White at al 2005 and Paneesha et al 2010) in which LC represented the most frequent carcinoma in cancer patients who developed VTE. In the population-based study by Sorensen et al (2000) LC was the most common tumor in the categories of patients analyzed: in those in whom cancer was diagnosed before, at the time or after an episode of VTE. Although other tumors have been associated with a greater thrombotic diathesis such as pancreatic or gastroesophageal cancers in previous reports by Levitan et al (1999) and Chew et al (2006), the higher incidence of LC in the general population make it the most common cancer associated with thrombosis in most of the series.

Our results also show that cancer and VTE were concurrently diagnosed in a higher proportion of patients with LC (18\%) compared to those with OC (8\%). This finding indicates another negative element in the epidemiology of VTE for patients with LC since it is known that survival is particularly poor when the diagnosis of cancer is concurrent with the VTE event in agreement with a previous report by Sorensen (2000) and also indicates the inability to prevent VTE in nearly one out of every 5 LC patients with VTE.

Interestingly, VTE was diagnosed earlier after cancer diagnosis in patients with LC compared to patients with OC. Our findings can be explained in part by the fact that all patients with LC have a thoracic CT for the initial evaluation of their disease resulting in a higher rate of PE diagnosis at the time of first cancer evaluation and thus representing a bias in relation to patients with OC. Likewise, the higher rate of unsuspected PE in patients with LC is probably due to a more frequent use of chest CT for the evaluation of cancer staging or response to chemotherapy in patients with LC. In addition, the higher proportion of patients with LC that presented with PE may be due to a higher rate of respiratory symptoms such as dyspnea or chest pain in patients withLC leading to a more frequent suspicion of PE in this setting.

However, other baseline traits such as the male gender, the smoking habit and the use of ESA (Crawford et al 2007 and Lippi et al 2010) may also influenced the excess risk of developing VTE in patients with LC. For 
instance, a retrospective study exploring the occurrence of VTE after pneumectomy for malignancy, Mason et al (2006) found that preoperative higher pack-years of smoking was associated with increased risk, as well as with earlier occurrence of venous thromboembolism. In our study patients with LC had more advanced cancer stages compared to those with OC. This is consistent with previous data indicating that an increased tumor burden is a known risk factor for the development of VTE in the cancer population. Moreover, different therapies including antineoplastic and supportive care medications according to tumor type might be responsible for increasing the risk of VTE. In the present study, patients with LC underwent less major surgery and more frequently received ESA compared to patients with OC, although no specific therapy was significant in the multivariate analysis. Taking all these observations into account, it seems plausible that patients with LC may have a more aggressive biological background that may confer a greater prothrombotic diathesis in parallel to a more unfavorable clinical course compared to patients with $\mathrm{OC}$ as demonstrated by the differences in survival outcomes. Thus, patients with LC represent a subgroup of particular interest among cancer patients in which the possible benefit of antithrombotic therapies should be prospectively assessed. The potential benefits of anticoagulants in patients with cancer is currently an area of great interest since the same biological mechanisms that promote the development of VTE are very closely linked to the processes of tumor growth and progression (Winter et al 2006). Tissue factor and the components of the clotting cascade are involved in tumor progression, invasion, angiogenesis, and metastasis formation as observed by Regina et al (2008) and reviewed by Kuderer et al (2009). Besides the efforts to stratify cancer patients for the risk of VTE in order to identify which patients would benefit from primary thromboprophylaxis in a previous study by Verso et al (2010), studies of the hemostatic system as a possible target for anticancer therapies are currently being developed. Future progress in this field may reveal opportunities for novel therapeutic interventions based on modulation of the activity of the coagulation system. Along this line, previous studies evaluating the impact of anti-thrombotic agents on improving survival in patients with small cell lung cancer have reported promising results (Zacharski et al 1981, Lebeau et al 1994 and Altinbas et al 2004) and new trials to assess the clinical benefits of adding heparin to the standard anticancer therapy in patients with LC are currently ongoing (Griffiths et al, 2009).

In a previous retrospective study by Blom et al (2004) the incidence of VTE was found to be three-fold higher in those with lung adenocarcinoma than in those with lung SCC. Moreover, Chew et al (2007) found that the independent predictors of developing VTE within one year after the diagnosis of NSCLC were: younger age, the number of chronic comorbidities, advanced TNM stage and adenocarcinoma histology. In fact, we have also observed that VTE among patients with LC occurred earlier in patients with adenocarcinoma as compared to other LC histologies, although patients with the former were also more likely to have metastatic disease and adenocarcinoma was not found to be an independent variable after Cox multivariate analysis.

In regard to VTE-related outcomes, although the clinical presentation of VTE in patients with LC was more frequent as PE, we did not observe differences in adverse outcomes directly related to the VTE event compared to patients with OC. After a longterm follow-up, we observed a trend towards a greater, albeit not statistically significant, venous rethrombosis in patients with LC compared to those with OC. Likewise, no differences were found in the occurrence of major bleeding complications and causes of death. Thus, overall, our study suggests that the prognosis of VTE in patients with LC and OC would be similar at short and long-term follow-up. However, in a considerable proportion of patients included in our study the VTE index event was diagnosed incidentally by scheduled CT scans. Clinically unsuspected PE during scheduled 
CT scans is found in about 5\% of all CT scans performed in cancer patients according to data by Browne et al (2010) and current international guidelines recommend to anticoagulate incidentallyfound VTE. It is of note, that nearly $50 \%$ of all PEs in our study were incidentallydiagnosed as previously reported by our group (Font et al, 2011) and in agreement with other studies by several authors worldwide (Sun et al 2010, Di Nisio et al 2010 and Singh et al 2010). This should be taken into account on interpreting our VTE-related outcomes and on comparing our findings with data from studies only including patients with symptomatic VTE (Monreal et al 2006).

A limitation of our study is that a high proportion of our patients died in palliative-care facilities outside our institution or were lost of follow-up. In addition, we did not routinely perform autopsies to all patients who died in our hospital. Consequently, it is difficult to be sure of the real incidence of 'venous rethrombotic events' during follow-up.

In summary, the present study provides new information on the epidemiology of thrombosis in cancer patients. Lung cancer was the most frequent tumor in our series and VTE occurred earlier in these patients after the diagnosis of cancer compared to OC. Highly significant differences were found in mortality, albeit not VTE-related, on comparing LC and OC patients. Nonetheless, we did not observe significant differences in either the short or long-term follow-up with respect to VTE-related outcomes. These findings suggest that the behavior of the underlying biological mechanisms in patients with LC may differ resulting in a higher clinical agressiveness in both the development of thrombosis and prognosis of the oncological process.

\section{References}

Altinbas, M., Coskun, H. S., Er, O., Ozkan, M., Eser, B., Unal, A., Cetin, M. \& Soyuer, S. (2004). "A Randomized Clinical Trial of Combination Chemotherapy with and without Low-Molecular-Weight Heparin in
Small Cell Lung Cancer," J Thromb Haemost, 2 (8) 1266-1271.

Blom, J. W., Osanto, S. \& Rosendaal, F. R. (2004). "The Risk of a Venous Thrombotic Event in Lung Cancer Patients: Higher Risk For Adenocarcinoma than Squamous Cell Carcinoma," J Thromb Haemost 2 (10) 1760-1765.

Browne, A. M., Cronin, C. G., English, C. et al. (2010). "Unsuspected Pulmonary Emboli in Oncology Patients Undergoing Routine Computed Tomography Imaging," J Thorac Oncol, 5 (6) 798-803.

Büller, H. R., Agnelli, G., Hull, R. D., Hyers, T. M., Prins, M. H. \& Raskob, G. E. (2004). "Antithrombotic Therapy for Venous Thromboembolic Disease: The Seventh ACCP Conference on Antithrombotic and Thrombolytic Therapy," Chest, 126 (3Suppl) 401S-428S.

Chew, H. K., Davies, A. M., Wun, T., Harvey, D., Zhou, H. \& White, R. H. (2007). "The Incidence of Venous Thromboembolism among Patients with Primary Lung Cancer," J Thromb Haemost, 6 (4) 601-608.

Chew, H. K., Wun, T., Harvey, D. et al. (2006). "Incidence of Venous Thromboembolism and its Effect on Survival among Patients with Common Cancers," Arch Intern Med 166 (4) 458-464.

Crawford, J., Robert, F., Perry, M. C. et al. (2007). "Anemia Prevention in NSCLC Group. A Randomized Trial Comparing Immediate versus Delayed Treatment of Anemia with Once-Weekly Epoetin Alfa in Patients With Non-Small Cell Lung Cancer Scheduled to Receive First-Line Chemotherapy," J Thorac Oncol, 2 (3) 210220.

Di Nisio, M., Ferrante, N., De Tursi, M. et al. (2010). "Incidental Venous Thromboembolism in Ambulatory Cancer Patients Receiving Chemotherapy," Thromb Haemost, 104 (5) 1049-1054.

Font, C., Farrús, B., Vidal, L. et al. (2011). "Incidental versus Symptomatic Venous Thrombosis in Cancer Patients: A 
Prospective Observational Study of 340 Consecutive Patients," Ann Oncol, 22 (9) 2101-2106.

Griffiths, G. O., Burns, S., Noble, S. I. et al. (2009). "FRAGMATIC: A Randomised Phase III Clinical Trial Investigating the Effect of Fragmin ${ }^{\circledR}$ Added to Standard Therapy in Patients with Lung Cancer," BMC Cancer Oct 6 (9) 355.

Jemal, A., Siegel, R., Ward, E. et al. (2009). "Cancer Statistics 2009," CA Cancer J Clin, 59 (4) 225-249.

Kearon, C., Kahn, S. R., Agnelli, G. et al. (2008). 'American College of Chest Physicians. Antithrombotic Therapy for Venous Thromboembolic Disease: American College of Chest Physicians Evidence-Based Clinical Practice Guidelines (8th Edition),' Chest, 133 (6Suppl): 454S$545 S$.

Khorana, A. A. (2010). "Venous Thromboembolism and Prognosis in Cancer," Thromb Research, 125 (6) 490493.

Klimpfinger, M., Green, F. L., Hutten, V. P. (1999). 'TNM Atlas: Illustrated Guide to the TNM/pTNM Classification of Malignant Tumors/UICC 4th ed (corrected 2nd ed),' Berlin, Germany: Springer-Verlag 1999.

Lebeau, B., Chastang, C., Brechot, J. M. et al. (1994). "Subcutaneous Heparin Treatment Increases Survival in Small Cell Lung Cancer," 'Petites Cellules' Group. Cancer, 74 (1) 38-45.

Lee, A. Y. Y. (2003). "Epidemiology and Management of Venous Thromboembolism in Patients with Cancer," Thromb Res, 110 (4) 167-172.

Levitan, N., Dowlati, A., Remick, S. C. et al. (1999). "Rates of Initial and Recurrent Thromboembolic Disease among Patients with Malignancy versus those without Malignancy. Risk Analysis Using Medicare Claims Data," Medicine (Baltimore), 78 (5) 285-291.
Lippi, G., Franchini, M. \& Favaloro, E. J. (2010). "Thrombotic Complications of Erythropoiesis-Stimulating Agents," Sem Thromb Hemost, 36 (5) 537-549.

Mason, D. P., Quader, M. A., Blackstone, E. H. et al. (2006). "Thromboembolism after Pneumectomy for Malignancy: An Independent Marker of Poor Outcome," J Thorac Cardiovasc Surg, 131 (3) 711-718.

Monreal, M., Falgà, C., Valdés, M. et al. (2006). "Fatal Pulmonary Embolism and Fatal Bleeding in Cancer Patients with Venous Thromboembolism: Findings from the RIETE Registry," J Thromb Haemost, 4 (9) 1950-1956.

Paneesha, S., McManus, A., Arya, R. et al. (2010). "Frequency, Demographics and Risk (According to Tumour Type or Site) of Cancer-Associated Thrombosis among Patients Seen at Outpatient DVT Clinics," Thromb Haemost, 103 (2) 338-343.

Prandoni, P., Falanga, A. \& Piccioli, A. (2005). "Cancer and Venous Thromboembolism," Lancet Oncol, 6 (6) 401-410.

Regina, S., Rollin, J., Bléchet, C. et al. (2008). "Tissue Factor Expression in Non-Small Cell Lung Cancer: Relationship with Vascular Endothelial Growth Factor Expression, Microvascular Density, and K-Ras Mutation," J Thorac Oncol, 3 (7) 689-697.

Rickles, F. R. (2006). "Mechanisms of Cancer-Induced Thrombosis in Cancer," Pathophysiol Haemost Thromb 35 (1-2) 103-110.

Seddighzadeh, A., Shetty, R. \& Goldhaber, S. Z. (2007). "Venous Thromboembolism in Patients with Active Cancer," Thromb Haemost, 98 (3) 656-661.

Singh, R., Sousou, T., Mohile, S. et al. (2010). "High Rates of Symptomatic and Incidental Thromboembolic Events in Gastrointestinal Cancer Patients," J Thromb Haemost, 8 (8) 1879-1881.

Siragusa, S., Arcara, C., Malato, A. et al. (2005). "Home Therapy for Deep Vein 
Thrombosis and Pulmonary Embolism in Cancer Patients," Ann Oncol, 16 Suppl 4:iv136-139.

Sorensen, H. T., Mellemkjaer, L., Olsen, J. H. et al. (2000). "Prognosis of Cancers Associated with Venous Thromboembolism," N Engl J Med, 343 (25) 1846-1850.

Sun, J. M., Kim, T. S., Lee, J. et al. (2010). "Unsuspected Pulmonary Emboli in Lung Cancer Patients: The Impact on Survival and the Significance of Anticoagulation Therapy," Lung cancer, 69 (3) 330-336.

Tagalakis, V., Levi, D., Agulnik, J. et al. (2007). "High Risk of Deep Vein Thrombosis in Patients with Non-Small Cell Lung Cancer: A Cohort Study of 493 Patients," J Thorac Oncol 2 (8) 729-734.

Tesselaar, M. E. T. \& Osanto, S. (2007). "Risk of Venous Thromboembolism in Lung Cancer," Disorders of Pulmonary Circulation. (2007) Curr Opin Pulm Med, 13 (5) 362-367.

Verso, M., Gussoni, G. \& Agnelli, G. (2010). "Prevention of Venous Thromboembolism in Patients with Advanced Lung Cancer Receiving Chemotherapy: A Combined Analysis of the PROTECHT and TOPIC-2 Studies," J Thromb Haemost, 8 (7) 16491651.

White, R. H., Chew, H. K., Zhou, H. et al. (2005). "Incidence of Venous Thromboembolism in the Year before the Diagnosis of Cancer in 528,693 Adults," Arch Intern Med, 165 (15) 1782-1787.

Winter, P. C. (2006). "The Pathogenesis of Venous Thromboembolism in Cancer: Emerging Links with Tumour Biology," Hematol Oncol, 24 (3) 126-133.

Zacharski, L. R., Henderson, W. G., Rickles, F. R. et al. (1981). "Effect of Warfarin on Survival in Small Cell Carcinoma of the Lung: Veterans Administration Study no. 75," JAMA, 245 (8) 831-835. 